\title{
ORIENTAÇÃO PROFISSIONAL NA ESCOLA: POSSÍVEL RELAÇÃO ENTRE TEORIA ESCOLAR E PRÁTICA PROFISSIONAL
}

Vinicius dos Santos Oliveira

Universidade do Oeste Paulista - UNOESTE, Curso de Psicologia, Presidente Prudente, SP. Universidade Estadual Paulista - FCTUNESP, Programa de Mestrado em Educação, Presidente Prudente, SP. E-mail: viniciusoliveira@unoeste.br

\section{RESUMO}

O presente ensaio sobre orientação profissional na escola começa pela apresentação de um rápido histórico sobre o surgimento da orientação profissional na escola como possibilidade de trabalho. Posteriormente, o texto trará, teoricamente, a atividade de orientação profissional no ambiente escolar, especificamente para adolescentes e, também, o papel da escola e do professor como partes ativas no processo de escolha de uma profissão. Por fim levantará uma discussão a respeito das práticas dos professores como eliciadores de práticas profissionais a partir da teoria transmitida aos alunos em sala de aula. Todo este trabalho tem como base teórica a psicologia históricocultural para discussão de possibilidades e descrição da orientação profissional como prática na escola, pois ela afirma que o desafio maior da escola é conseguir preparar o adolescente para o trabalho ao mesmo tempo em que não limita a educação escolar a este trabalho e sim na formação de um individuo autônomo para o trabalho e para a vida.

Palavras-chave: Orientação Profissional; Orientação Profissional Na Escola; Orientação Profissional Histórico-Cultural.

\section{ORIENTATION PROFESSIONAL SCHOOL: POSSIBLE RELATIONSHIP BETWEEN THEORY AND PROFESSIONAL PRACTICE SCHOOL}

\section{ABSTRACT}

This essay on career guidance in school begins with the presentation of a brief account of the emergence of vocational guidance in school as a possibility to work. Later, the text will theoretically career guidance activity in the school environment, specifically for teenagers and also the role of schools and teachers as active parts in the choice of a profession process. Finally raise a discussion of teachers' practices as elicitors of professional practices from the theory transmitted to students in the classroom. All this work is theoretical basis to historical and cultural psychology to discuss possibilities and description of the vocational guidance and practice in school, because she says that the biggest challenge school is to prepare adolescents for work while not limiting school education for this job, but the formation of an autonomous individual for work and life.

Keywords: Career Counseling; Career Guidance In Schools; Historical And Cultural Guidance.

\section{INTRODUÇÃO}

Este ensaio visa apresentar uma breve discussão sobre a orientação profissional na escola, tendo o professor como chave para o desenvolvimento do interesse profissional do aluno. Será descrito um breve histórico do surgimento da orientação profissional, bem como, serão descritas atividades de orientação profissional na escola. Por fim, haverá uma consideração do autor sobre a necessidade de atividades teóricas escolares com aplicação prática.

A modalidade de pesquisa utilizada foi a de pesquisa bibliográfica, visando uma revisão acerca do tema. Para as pesquisas foram feitas buscas em artigos, teses e dissertações que abordem o assunto, principalmente, a partir da perspectiva histórico-cultural ou sócio-histórica. Foi possível perceber que há poucos trabalhos nestas abordagens, por isso para melhor compreensão do assundo, foram utilizados textos de outros autores.

\section{ORIENTAÇÃO PROFISSIONAL: BREVE HISTÓRICO}

A orientação profissional teve seu inicio no século XX com Frank Parsons, no Vocational Bureau of Boston. O objetivo central dela é o de orientar jovens na escolha da carreira (AMBIEL; POLLI, 2011). A função do orientador é, neste contexto, ajudar o sujeito a refletir sobre si mesmo e seus anseios referentes ao trabalho e à profissão. Ajudar ainda, no esclarecimento de 
questões a respeito de empregos, profissões, empresas e do mundo do trabalho que se apresenta à sua volta (SOARES et al., 2007).

Bock (2006) retoma em seu trabalho a história da Orientação Profissional. Descreve que é uma questão atual na história da humanidade, pois os homens ancestrais trabalhavam também de forma coletiva, mas não tão organizada como na atualidade. Relembra que na Grécia antiga uma das atividades apreciadas e valorizadas pelo ser humano era o ócio. $O$ ócio era atividade de homens livre e o trabalho era atividade de escravos, onde estes trabalhadores ficavam responsáveis pela criação de materiais para a sobrevivência.

A atividade ou trabalho a ser desenvolvido por alguém era, sobretudo, definida pela classe que sua família ocupava na sociedade. Também, isso aconteceu na idade média com a divisão de classes entre clérigos, nobres e vassalos. Nesse período a atividade ainda não tinha como fim o mercado, porque esta ainda estava em processo de surgimento (BOCK, 2006).

O mesmo autor afirma que nesta mesma época não se falava em escolha de profissão, pois o que a determinava a "careira" era a classe em que a família do sujeito estava inserida. Havia o poder da igreja sobre a sociedade que definia o trabalho como vocação, chamado de Deus e que não podia ser questionado. Assim, o trabalho tinha primariamente caráter de sobrevivência material, onde cada produtor era proprietário do instrumento que utilizava, mas dividia o que produzia com o proprietário da matéria prima e da terra.

Segundo Bock (2006) a orientação profissional entrou em cena e ganhou importância quando se firmou o formato de sociedade capitalista. Neste sistema o trabalhador e os meios de produção passam a ser dominados pelos nobres e senhores. Nesse sentido o trabalhador passa a vender sua capacidade e sua força de trabalho. Com isso, também, aparece a produção com vistas ao mercado e à geração de lucro.

Conforme Lima (2007) com a Revolução Francesa de 1789 e a Revolução Industrial de 1837, ocorreram mudanças na forma de se olhar para o trabalho e para o trabalhador. Segundo ela, os gritos por direito e liberdade da foram essenciais para o surgimento da orientação profissional e a partir de 1837, surgiu a necessidade de aprimoramento da atividade de trabalho, o que faz com que a orientação comece a ser necessária, pelo fato de cada atividade necessitar de determinadas habilidades específicas.

Tempos depois houve a Revolução Industrial que inseriu no formato de produção capitalista a divisão do trabalho. Isso fez - e permanece até os dias hodiernos - com que o trabalhador para cada área da linha de produção seja selecionado por competências e assim surge a necessidade da escolha profissional, juntamente ao pensamento de ter o 'homem certo no lugar certo' para aumentar a produtividade (BOCK, 2006).

A chamada vocação que prevaleceu no sistema feudal caiu por terra e a burguesia emergente, por sua vez, tentava difundir a ideia de igualdade, fraternidade e liberdade entre os Homens. Isso demonstra que a escolha profissional não nasce com o individuo, não é natural e sim construída pela sociedade, em especial, na sociedade capitalista.

\section{ORIENTAÇÃO PROFISSIONAL NA ESCOLA}

Para Oliveira e Anjos (2011) o maior desafio da orientação profissional para adolescentes escolares é conseguir prepará-los para a atuação no mundo do trabalho e ao mesmo tempo não limitar a formação deste indivíduo a um processo de mera adaptação ao mercado de trabalho. Não se pode reduzir a formação do indivíduo a um processo de reprodução da força de trabalho, nem, também, ignorar o fato de que vivemos numa sociedade capitalista com o trabalho dividido em funções, cargos e tarefas e que todos precisam sobreviver e para isso precisam de renda, emprego.

Para estes autores a orientação profissional deve possibilitar ao adolescente estudante uma análise histórica, social e cultural das escolhas profissionais e de carreira. Ela necessita apresentar a estes jovens as contradições da sociedade capitalista para deixalos a par da situação da alienação causada pelo trabalho, visto que o processo de alienação no trabalho inicia-se quando o sujeito se sente estranho à sua própria atividade e não vê sentido e nem significano no que realiza.

No sistema capitalista, a classe mais baixa, vive em condições sociais e econômicas precárias e são excluídas. E é por isso que a orientação profissional deve auxiliar, sobretudo, os jovens de classe baixa. (OLIVEIRA; ANJOS, 2011). Nesse caso é importante a realização de um processo de orientação no sentido de 
proporcionar a possibilidade de um pensamento crítico aos jovens dando-lhes a possibilidade de entender o contexto em que vive em relação às suas aspirações profissionais.

Devido a atual conjuntura, proporcionada pelo capitalismo, muitos dos adolescentes brasileiros entram no mundo do trabalho sem ter possibilidade de passar por um processo de escolha profissional. Entram pela necessidade de obter um emprego e aceitam aquilo que thes oferecem apenas por necessidade de sobrevivência material (OLIVEIRA; ANJOS, 2011).

Oliveira e Anjos (2011) citam Vygotski

(1995), que afirma que estudar algo historicamente, é também, estudar a história em movimento. Vigotski diz que, a história, sempre está em movimento, em um movimento dialético. Nesse caso, a orientação profissional deve buscar a relação que há entre os fatos históricos e identificar conceitos que se formaram no sujeito a partir disso.

O trabalho de Oliveira e Anjos (2011) apresentam três aspectos importantes a serem discutidos em uma orientação profissional com base na Psicologia Histórico-Cultural: primeiro a necessidade de superar a visão naturalizante do ser humano; segundo a necessidade da superar a visão que separa indivíduo e sociedade; e por fim, a necessidade de desmistificar os pressupostos que defendem que o ser humano pode escolher sua profissão, independentemente das condições socioculturais em que vive. Por isso, é necessário que se discuta o processo de orientação profissional como um movimento dialético, interdependente, com múltiplas-determinações no tocante à escolha profissional.

Os autores supracitados se utilizam ainda, do conceito de Zona do Desenvolvimento Proximal descrito por Vigotskii, para dizer que a orientação profissional baseada nesta perspectiva não deve trabalhar somente com os conteúdos que trazem os orientandos e sim a partir deles, proporcionar ao orientando um salto qualitativo em relação aos novos conteúdos apresentados para reflexão e desenvolvimento das escolhas profissionais.

O ser humano na perspectiva de Vigotski e Leontiev é um ser dialético, por isso para Oliveira (2009) o processo de escolha profissional também é. Por isso é importante que seja abordado qual sentido atribuído à escolha da profissão, visto que ela é também influenciada pelo contexto - ambiente físico e social do individuo. Por isso, orientação profissional pode ajudar o ingressante no mundo do trabalho a compreender suas aptidões e anseios de acordo com o contexto em que está.

Na psicologia sócio-histórica a orientação profissional centra-se na saúde do trabalhador, visando dar oportunidade ao individuo de refletir a cerca de seu futuro sempre levando em conta o contexto em que o orientando está. Deve possibilitar a crítica, o questionamento e a confrontação de ideais do individuo e a realidade na qual ele se encontra. Também tem a função alertá-lo a respeito da situação do mercado, como, por exemplo, a pressão e as cobranças advindas do capitalismo. Contudo, sempre se enfatiza as capacidades, esforços e desejo deste frente à sua escolha (OLIVEIRA, 2009).

Aita, Ricci e Tuleski (2013) realizaram um trabalho com alunos do ensino médio de uma escola pública do município de Maringá-PR. O projeto consistiu-se na realização de um processo de orientação profissional fundamentado no referencial teórico da Psicologia HistóricoCultural. Foi feito um trabalho junto à equipe pedagógica e os professores. Participaram deste estudo seis turmas do primeiro ano, sete turmas de segundo ano e cinco turmas do terceiro ano com em média de 25 alunos do Ensino Médio.

O objetivo da pesquisa supracitada foi levar informações sobre profissões e áreas de conhecimento para promover o desenvolvimento da consciência e desenvolvimento de conceitos científicos sobre o tema. Com a promoção de conhecimento propiciar o desenvolvimento por meio da apropriação das riquezas produzidas historicamente. Nesse sentido, atuar na zona de desenvolvimento imediato introduzindo ao contexto dos alunos informações sobre o mundo do trabalho (AITA; RICCI; TULESKI, 2013).

A sociedade capitalista traz consigo muitas contradições entre elas a disseminação da alienação, também a perca de sentido e significado do trabalho para o trabalhador, por isso a pesquisa supramencionada buscou inserir no contexto dos jovens participantes o conhecimento sobre o sentido e o significado da profissão em relação à instancia particular e social (AITA; RICCI; TULESKI, 2013).

Neste caso, a psicologia histórico-cultural tenta modificar a ideia de que o indivíduo nasce com determinado dom ou talento e deve segui-lo profissionalmente. Ela crê na ideia de que os interesses, as motivações para a escolha profissional surgem no contexto coletivo. Assim a realização desta atividade irá se basear na 
relação entre as categorias de sentido e significado (AITA; RICCl; TULESKI, 2013).

\section{CONSIDERAÇÕES FINAIS}

Por conseguinte, este ensaio propõe um trabalho de compreensão da função da escola no processo de escolha da profissão para jovens e adolescentes escolares. Capacitar professores para trabalhar com a formação do sentido de escolha de uma profissão desde a escola.

O ser humano passa por algumas fases do desenvolvimento e em cada um dessas etapas existem atividades que guiam seu desenvolvimento. Na primeira infância as atividades que promovem o desenvolvimento são as atividades de (1) comunicação emocional do bebe, em que ele se comunica com seus cuidadores por meio de choro e sorriso e também a atividade (2) manipulatória objetal em que a criança, aprende por meio do contato com os objetos. Já na segunda infância são outras duas atividades que são os (3) jogos de papeis, em que a criança brinca de ser o que o adulto é e que ela ainda não tem capacidade de ser, como por exemplo, brincar de professor ou de médico e a (4) atividade de estudo, na qual a criança vai para a escola e lá encontra novas atividades e suas primeiras responsabilidades. E por fim ao entrar na adolescência, as duas ultimas etapas que têm como principais as atividades de (5) comunicação intima pessoal do adolescente, onde ele começa a se relacionar com seus pares e formar juízos sobre o mundo e por fim a atividade de profissional e de estudo que ocorre da adolescência e juventude em diante, em que o indivíduo encontra-se no período de escolher sua carreira, sua faculdade, suas atividades profissionais (ANJOS, 2013).

A atividade de estudo e profissional tem um novo sentido para o adolescente. Começa a preparação para uma vida futura. O motivo fundamental para a atividade de estudo é a possibilidade de uma futura profissão, como visto anteriormente. Por isso, a aquisição de conhecimentos por meio da educação escolar é indispensável para que $o$ adolescente se conscientize dos direitos da futura vida de trabalho (ANJOS, 2013).

Conforme Anjos (2013), papel da educação escolar neste contexto é importante. Diz o autor que a atitude seletiva dos adolescentes passa a ser dirigida para determinados e diferentes campos de conhecimento. Volta-se para as ciências sociais, técnicas ou biológicas, por exemplo. Neste caso, os adolescentes manifestam uma relação entre os interesses e a escolha da profissão. É o interesse que vai fazer com que o adolescente busque conhecer mais profundamente uma profissão em determinado campo do conhecimento.

O mesmo autor relata em sua dissertação que há casos de disparidade entre os interesses e a escolha da profissão. Ele atribui tal evento à especificidade da educação escolar. Um dos motivos é porque o aluno não consegue compreender a relação entre a teoria de seu interesse e a atividade prática. Por exemplo, qual a importância de se aprender língua portuguesa na escola o futuro profissional, ou química, física entre outras.

Diante disso é importante dizer que os adolescentes têm dificuldade de abstração e análise da relação que há entre os conteúdos escolares e a escolha de uma profissão. Por isso, fica evidente a necessidade de o trabalho educativo propiciar ao adolescente o pensamento teórico, mas com maior exigência no sentido de gerar maior grau de generalização e abstração do conhecimento, pois é a escola que proporciona aos alunos a abstração de novos conceitos.

As politicas educacionais estão mais focadas em preparar os formandos com intenção de satisfazer a necessidade do mercado, do que em desenvolver uma atividade mais complexa com vistas realização de novas profissões escolhidas de forma autônoma pelo próprio sujeito. Seria importante que em suas disciplinas, os professores conseguissem inserir exemplos práticos de profissões, como por exemplo, explicar que para a maior parte das profissões, a língua portuguesa é extremamente solicitada ou que para as engenharias, as disciplinas de química, física, matemática são importantíssimas.

Isso para não se limitar a formar pessoas para trabalharem de forma a reproduzir apenas uma atividade em que não encontra sentido e nem significado e realizar. Pois os conhecimentos científicos, artísticos e filosóficos produzidos historicamente pela humanidade, quando são transmitidos pelo professor ao aluno e apropriados por eles, contribuem, para uma relação mais consciente do individuo com a cotidianidade.

Neste mesmo sentido, Mouta e Nascimento (2008) apontam que é preciso que o professor em sala de aula promova atividades 
que estimulem os alunos a quererem conhecer as profissões relacionadas às disciplinas. $E$ ao mesmo tempo promover uma capacidade critica nos alunos. O professor pode ser mais importante ainda, em relação à escolha profissional, ao promover atividades que coloquem os alunos diretamente em contato com tais profissões.

Nesse caso, sabe-se que há a necessidade haver treinamentos e capacitações que ajudem os professores a pensarem formas inovadoras e atualizadas de apresentar os conteúdos aos seus alunos. É preciso capacitar estes professores para poderem explorar os desejos dos alunos em relação a profissões sempre havendo uma relação entre o conteúdo teórico com a atividade prática e profissional.

Qual é o sentido de aprender tantas disciplinas dispostas nos currículo escolares, sendo que nenhuma delas propõe - nem por meio de exemplos - uma aplicação do conteúdo? Por que não explicar que a física, a matemática, a biologia, as línguas, a geografia e outras têm a ver com uma profissão que o jovem pode escolher futuramente.

Ser profissional de alguma área exige interesse pela atividade, do contrário, não é possível haver saúde no trabalho. A Satisfação de uma pessoa durante a realização de uma atividade profissional está na liberdade sentida por ela durante a atividade. A escolha com liberdade pode ser alcançada, também, com apoio de um orientador profissional, mas ao mesmo tempo a escola pode contribuir com esse processo.

\section{REFERÊNCIAS}

AMBIEL, R. A. M.; POLLI, M. F. Análise da produção científica brasileira sobre avaliação psicológica em orientação profissional. Estudos interdisciplinares em Psicologia, Londrina, v.2, n.1, p.103-121, jun. 2011.

AITA, E. B.; RICCI, P. S. P.; TULESKI, S. C. A orientação profissional na perspectiva da psicologia histórico-cultural. Revista Semestral da Associação Brasileira de Psicologia Escolar e Educacional, v.16, p.175-177, 2012. http://dx.doi.org/10.1590/S1413-

85572012000100019

ANJOS, R. E. O desenvolvimento psíquico na idade de transição e a formação da individualidade para-si: aportes teóricos para a educação escolar de adolescentes. 2013. Dissertação (Mestrado em Educação Escolar) -
Universidade Estadual Paulista, Faculdade de Ciências e Letras, Araraquara - SP.

BOCK, S. D. Orientação profissional a abordagem sócio-histórica. 3. ed. São Paulo: Cortez, 2006.

LIMA, M. T. Orientação profissional: princípios teóricos, práticos e textos para psicólogos e educadores. 1. ed. São Paulo: Vetor, 2007.

MOUTA, A.; NASCIMENTO, I. Os (novos) interlocutores no desenvolvimento vocacional de jovens: uma experiência de consultoria a professores. Revista Brasileira de Orientação Profissional, v.9, n.1, p.87-101, 2008.

OLIVEIRA, A. S. Os sentidos da escolha da profissão, por jovens de baixa renda: um estudo em psicologia sócio-histórica. 2009. 173p. Dissertação (mestrado em Educação) - Psicologia da Educação, Pontifícia Universidade Católica de São Paulo - SP.

OLIVEIRA, M. B. L.; ANJOS, R. E. Aportes teóricos da psicologia sócio-histórica para a pesquisa e intervenção em orientação profissional: a escolha profissional em questão. Avesso do Avesso, Araçatuba, v.9, n.9, p. 20-34, nov. 2011.

SOARES, D. H. P. et. al. A orientação profissional nas empresas francesas e seu paralelo no Brasil: questões para 0 orientador profissional Brasileiro. Estudos e Pesquisas em Psicologia, versão On-line, Rio de Janeiro, v.7 n.3, dez. 2007.

Recebido para publicação em 20/08/2015

Revisado em 14/03/2015

Aceito em 07/06/2016 